\title{
Rapid screening mutations of first-line-drug-resistant genes in Mycobacterium tuberculosis strains by allele-specific real- time quantitative PCR
}

\author{
Pengpeng Yang ${ }^{1}$, Yuzhu Song ${ }^{1}$, Xueshan Xia ${ }^{1}$, A-Mei Zhang ${ }^{\text {Corresp. }}{ }^{1}$ \\ ${ }^{1}$ Faculty of Life Science and Technology, Kunming University of Science and Technology, Kunming, China \\ Corresponding Author: A-Mei Zhang \\ Email address: zam1980@yeah.net
}

Tuberculosis (TB) is a worldwide health, economic, and social burden, especially in developing countries. Drug-resistant TB (DR-TB) is the most serious type of this burden. Thus, it is necessary to screen drug-resistant mutations by using a simple and rapid detection method. A total of 32 pairs of Allele-specific PCR (AS-PCR) primers were designed to screen mutation and/or wild-type alleles of 16 variations in four first-line drug-resistant genes ( $k a t G, r p o B, r p s L$, and $e m b B$ ) of TB strains. A pair of primers was designed to amplify $16 \mathrm{~S}$ rRNA gene and to verify successful amplification. Subsequently, we tested the specificity and sensitivity of these AS-PCR primers. The optimized condition of these ASPCR primers was first confirmed. All mutations could be screened in general AS-PCR, but only 13 of 16 variations were intuitively investigated by using real-time quantitative PCR and AS-PCR primers. The results of specificity assay suggested that the AS-PCR primers with mutation and /or wildtype alleles could successfully amplify the corresponding allele under optimized PCR conditions. The sensitivity of nine pairs of primers was 500 copy numbers, and the other seven pairs of primers could successfully amplify correct fragments with a template comprising $10^{3}$ or $10^{4}$ copy numbers template. An optimized AS-qPCR was established to screen drug-resistant mutations in TB strains with high specificity and sensitivity. 
1 Rapid screening mutations of first-line-drug-resistant genes in Mycobacterium tuberculosis

2 strains by allele-specific real-time quantitative PCR

3

4 Pengpeng Yang ${ }^{1}$, Yuzhu Song ${ }^{1}$, Xueshan Xia ${ }^{1}$, A-Mei Zhang 1,*

5

$6{ }^{1}$ Faculty of Life Science and Technology, Kunming University of Science and Technology,

7 Kunming, Yunnan, China

8

9

$10 *$ Corresponding author

11 Dr. A-Mei Zhang, Molecular virus Units, Faculty of Life Science and Technology, Kunming

12 University of Science and Technology, Kunming, Yunnan 650500, China. Tel/Fax: 86-871-

13 65920756; E-mail: zam1980@yeah.net 


\section{Abstract}

16 Tuberculosis (TB) is a worldwide health, economic, and social burden, especially in developing

17 countries. Drug-resistant TB (DR-TB) is the most serious type of this burden. Thus, it is

18 necessary to screen drug-resistant mutations by using a simple and rapid detection method. A

19 total of 32 pairs of Allele-specific PCR (AS-PCR) primers were designed to screen mutation

20 and/or wild-type alleles of 16 variations in four first-line drug-resistant genes ( $k a t G, r p o B, r p s L$,

21 and $e m b B$ ) of TB strains. A pair of primers was designed to amplify $16 \mathrm{~S}$ rRNA gene and to

22 verify successful amplification. Subsequently, we tested the specificity and sensitivity of these

23 AS-PCR primers. The optimized condition of these AS-PCR primers was first confirmed. All

24 mutations could be screened in general AS-PCR, but only 13 of 16 variations were intuitively

25 investigated by using real-time quantitative PCR and AS-PCR primers. The results of specificity

26 assay suggested that the AS-PCR primers with mutation and /or wildtype alleles could

27 successfully amplify the corresponding allele under optimized PCR conditions. The sensitivity of

28 nine pairs of primers was 500 copy numbers, and the other seven pairs of primers could

29 successfully amplify correct fragments with a template comprising $10^{3}$ or $10^{4}$ copy numbers

30 template. An optimized AS-qPCR was established to screen drug-resistant mutations in TB

31 strains with high specificity and sensitivity.

33 Keywords: AS-qPCR; drug-resistant mutations; TB; specificity and sensitivity 
35

36

37

\section{Introduction}

Tuberculosis (TB) is a disease with high prevalence and mortality rate. It is caused by Mycobacterium tuberculosis (M. tuberculosis) infection. One-third of the world population is infected with M. tuberculosis, and 5\% of infected people developed into TB in their lifetime (Comstock et al. 1974; Koul et al. 2011). In 2017, 10.1 million people suffered from TB, among which 1.6 million people died. Though morbidity and mortality of TB gradually decreased with the appearance of anti-TB drugs, the mutation rate of drug-resistant genes in M. tuberculosis seemed to increase recently. The cost of TB treatment and research reached 10.4 billion $\$$ in 2018. Half of this amount was used to treat drug-resistant TB (DR-TB) patients (WHO 2018).

In the middle of 20th century, DR-TB strains were reported for the first time (Crofton \& Mitchison 1948). Unfortunately, the researchers did not focus on this phenomena at that time (Zignol et al. 2016). Recently, the number of patients with DR-TB, especially those with multiple drug-resistant TB (MDR-TB), seriously increased. The numbers of patients with MDRTB reached 160, 684 in 2017. A total of 10, 800 cases of extensive drug-resistant TB (XDR-TB) were reported by 77 countries, and 88\% XDR-TB cases were from European and South-East Asia regions (WHO 2018). Due to abuse of antibiotics and environmental disruption, drugresistant TB strains have turned out to be barriers to tuberculosis treatment.

First-line anti-TB drugs, including isoniazid, rifampicin, streptomycin, ethambutol, and pyrazinamide, are still widely used in clinic. Inevitably, drug-resistant genes exist in $M$. tuberculosis, thereby allowing it to resist first-line anti-TB drugs. kat $G$ and inh $A$ genes are two 
common candidate genes in isoniazid (INH) -resistant TB strains. Mutations in other genes, such as sigI, $n d h$, and others, also reportedly to lead to INH-resistance in TB (Guo et al. 2006). Similarly, $r p o B, e m b B, r p s L$, and $p n c A$ were major drug-resistant genes for Rifampicin (RIF)-, Ethambutol (EMB)-, Streptomycin (SM)-, and Pyrazinamide (PZA)- resistant TB strains (Lee et al. 2012; Sandy et al. 2002; Zhang \& Yew 2009). Although the mutant spectra showed distinction in different countries, there were some hotspot mutations in these candidate genes.

61 The mutation at codon 315 of the $k a t G$ gene was the most popular INH-resistant mutation, and more than $50 \%$ of INH-resistant mutations located in this codon (Afanas'ev et al. 2007; Yuan et al. 2012). Most of RIF-resistant mutations located in hotspot region of the $r p o B$ gene, but the mutant frequency varied from $75 \%$ to $90 \%$ in different countries (Franco-Sotomayor et al. 2018; Thirumurugan et al. 2015). Mutations at codon 43 and 88 were two common SM-resistant mutations in the rps $L$ gene, and over 65\% SM-resistant TB strains were caused by these two mutations (Tudo et al. 2010; Zhao et al. 2015). About 70\% of EMB-resistant TB strains had mutations which located at codon 306, 406, or 497 in the embB gene (Brossier et al. 2015). Thus, rapid screening these mutations was necessary. Long-time and inappropriate drug usage could lead to drug-resistance. Thus, rapid and convenient diagnosis of drug-resistant TB patients is necessary for further effective treatment. Based on the drug-resistant mutations (including hotspot and rare mutations) in our previous study (Li et al. 2017), we established an optimized allele-specific real-time quantitative PCR

74 (AS-qPCR) method to screen mutations in drug-resistant TB strains rapidly and with high 
75 sensitivity and specificity.

\section{Materials and Methods}

\subsection{M. tuberculosis strains collection and DNA extraction}

performed by using the following drugs: INH, $0.2 \mathrm{mg} / \mathrm{L}$; RIF, $40 \mathrm{mg} / \mathrm{L}$; SM, $4.0 \mathrm{mg} / \mathrm{L}$; EMB,

to extract genomic DNA from M. tuberculosis strains according to the manufacturer's of Science and Technology (Approval No. 2014SK027).

\subsection{Primer design and AS-PCR optimization}

A total of 32 pairs of primers for AS-PCR were designed to screen the 16 variations

(including mutation and wild-type alleles), which were located in four genes ( $k a t G, e m b B, r p s L$, and $p n c A$ ), by using Oligo Primer Analysis Software v.7 (Table S1). To strengthen the specificity of primers, a non-complementary nucleotide in 3' end of the allele-specific primer was factitiously changed and marked in red in Table S1. One pair of inner control primers (16S 
95 mutation sample. The sensitivity results were determined based on the appearance and intensity

114 of the products on the agarose gel. Moreover, wildtype AS-PCR primers were also used to

2×TSINGKE ${ }^{\mathrm{TM}}$ Master Mix (including $1 \mathrm{U}$ DNA polymerase, $1.5 \mathrm{mM} \mathrm{MgCl}_{2}, 50 \mathrm{mM} \mathrm{KCl}$, and $100 \mathrm{mM}$ dNTP) (TSINGKE, China) or ChamQ ${ }^{\mathrm{TM}}$ SYBR qPCR Master Mix (Vazyme, China), and 0.5 $\mu \mathrm{M}$ each primer (including AS-PCR primers and internal control primers). After optimization, we used the following PCR condition: one cycle of $95{ }^{\circ} \mathrm{C}$ for $3 \mathrm{~min}$; 35 cycles of $95{ }^{\circ} \mathrm{C}$ for $30 \mathrm{~s}$, optimized temperature for $30 \mathrm{~s}$ (Table S1), $72{ }^{\circ} \mathrm{C}$ for $10 \mathrm{~s}$; and one extension cycle of $72^{\circ} \mathrm{C}$ for $5 \mathrm{~min}$.

\subsection{Plasmids construction}

Five pairs of primers (Table S2) were designed to amplify fragments containing all mutations. PCR amplification products were ligated into the pClone 007 Blunt Simple Vector by using pClone 007 Vector Kit (TSINGKE, China). All constructed plasmids were identified to carry the specific mutation or wildtype allele by sequencing. Plasmid extraction small Kit (TIANGEN, China) was used to purify the plasmids.

\subsection{Specificity and sensitivity tests}

We amplified 14 wildtype TB samples (identified by sequencing) and all templets of each mutation to test the specificity of AS-PCR by using both wildtype and mutation primers. If there was only one sample with a certain mutation, we duplicated the AS-PCR by using the same 
115 amplify plasmids with corresponding mutations. After qualifying the plasmids, we diluted

116 plasmids to $10^{4}, 10^{3}$, and $5 \times 10^{2}$ copy numbers to achieve a sensitive assay.

$118 \quad 2.5$ AS real-time quantitative PCR

119 According to the results of optimized AS-PCR, we performed AS real-time quantitative

120 PCR (AS-qPCR) assays, in order to directly detect the products and determine the mutation or

121 wild type allele. PCR was performed in $20 \mu \mathrm{L}$ reaction volume and involved $30 \mathrm{ng}$ of genomic

122 DNA, ChamQTM SYBR qPCR Master Mix (Vazyme, China), and $0.3 \mu \mathrm{M}$ each primer

123 (including mutation and wild type AS-PCR primers of each allele) on Takara Thermal Cycler

124 Dice Real Time System TP800 (TaKaRa, Japan).

125

126 3. Results

127 A total of 16 point mutations in four first-line drug-resistant genes were used to establish

128 AS-PCR detecting method, which were identified in 57 drug-resistant M. tuberculosis strains by

129 sequencing in our previous study (Li et al. 2017). After optimizing the conditions of PCR with

130 these primers, we obtained concordant results by sequencing, i.e. the correct bands were

131 successfully amplified by using mutant AS-PCR primers and mutation template but not wild-

132 type samples, and vice versa (Fig. 1). The specificity test results suggested all primers in this

133 study could identify the mutation or wildtype alleles with high fidelity (Fig. S1). As shown in

134 Figure 2, a 206 bp fragment could be amplified by using samples with wild-type rps $L$ gene and 
135 primers $R p s L$ 128A-F/RpsL 128-R (the primer for wild-type allele A at amino acid codon 128).

136 However, this amplicon did not exist when samples with $\operatorname{rps} L 128 \mathrm{G}$ were used. On the contrary,

137 the primers RpsL 128G-F/RpsL 128-R (for mutant allele G) could amplify a 206 bp fragment

138 when the samples carried the mutation allele $128 \mathrm{G}$ in the $r p s L$ gene. The presentation of the 104

139 bp inner control fragment suggested a successful amplification.

140 Plasmids with mutation and wildtype alleles were constructed to evaluate the sensitivity of

141 AS-PCR primers. As shown in Figure 3, the sensitivity of primers for amino acid codon 128 in

142 the $\operatorname{rps} L$ gene was estimated by using a plasmid with $10^{4}, 10^{3}$, and $5 \times 10^{2}$ copy numbers. When

143 the copy number of the plasmids was $5 \times 10^{2}$, we could visualize a faint band. However, the bands

144 were obvious and clear when we increased the plasmids to $10^{3}$ or $10^{4}$ copy numbers. The

145 sensitivity of all 32 pairs of primers were tested, and half of these primers could amplify an

146 observable band when the plasmid copy number was $5 \times 10^{2}$ (Fig. S2). However, the others

147 needed more copy numbers $\left(10^{3}\right.$ or $10^{4}$, Fig. S2 and Table S1).

148 To directly and rapidly investigate the testing results of AS-PCR, we combined AS-PCR

149 primers and real-time quantitative PCR for subsequent observation. By observing the melt-curve

150 of these products, we determined whether mutations existed. We firstly defined the baseline at

151100 relative fluorescence units (RFU)/min as the detecting level. According to this standard, we

152 tested all 16 mutations by using AS-qPCR. However, only 13 mutations were rapidly and

153 directly genotyped (Fig. S3). As shown in Figure 4, we could rapidly identify the allele at 128

154 nucleotide in the rpsL gene. By using the optimized AS-qPCR, we rapidly distinguished the 
mutation and/or wild-type allele in one PCR reaction with two pairs of primers.

156

157

\section{Discussion}

158

China is among the top 22 countries with the highest burden of TB and with the second

highest burden of DR-TB. About 120,000 persons developed into TB in China each year (Du et

160

al. 2017; Zhao et al. 2012). Many factors could lead to DR-TB, such as contaminative

161

environment, drug abuse, long-time therapy, and host genetic factors. Some TB strains might

162

change to drug-resistance or solo DR-TB might develop to XDR-TB after the long-term

163

treatment of TB patients. Thus, it was important and necessary to rapidly diagnose DR-TB,

164

especially for first-line DR-TB. Point mutations of drug-resistant genes were common reasons

165

for the development of first-line DR-TB strains. Mutations in the $k a t G$ and/or $i n h A$ gene were the

two main causes of INH-resistant TB. About 51\% and 10\% isoniazid-resistant TB strains were

167

caused by mutations in the kat $G$ and $i n h A$ genes, respectively (Guo et al. 2006). Mutations in the

$r p o B$ gene, $r p s L$ gene, $e m b B$ gene, and $p n c A$ gene were the main factors for RIF- resistant, SM-

169

resistant, EMB- resistant, and PZA- resistant TB strains, respectively (Brossier et al. 2015;

Scorpio \& Zhang 1996; Stoffels et al. 2012; Villellas et al. 2013). Furthermore, some hotspot

171 mutations still exist in these drug-resistant genes (Banerjee et al. 1994; Dalla Costa et al. 2009;

172 Lee et al. 2012; Seifert et al. 2015; Waagmeester et al. 2005). Most commercialized detecting

173 kits for DR-TB strains only contained hotspot mutations. Hence, some rare mutations might be

174 missed. In our previous study, we identified some mutations in these genes of Yunnan DR-TB 
175 strains, and some of them were hotspot mutations and others were rare mutations (Li et al. 2017).

176 Because no hotspot mutation has been found in the $p n c A$ gene, eighteen mutations of the other

177 four genes (including $k a t G, r p o B, r p s L$, and $e m b B$ genes) were used as candidate mutations in

178 this study. Unfortunately, two mutations, including G1388T (at codon 463) in the katG gene and

179 A1490G (at codon 497) in the $e m b B$ gene, could not genotyped by using AS-PCR. Thus, it

180 seemed that not all drug- resistant mutations could be well detected by using AS-PCR.

181 DST is the classic method and the "gold standard" for the evaluation of drug-resistant TB

182 strains (Ahmad \& Mokaddas 2009). Until now, DST is still widely used in laboratory and

183 hospital, but methods to screen mutations of drug-resistant genes were speedily developed after

184 invention of PCR. Multi-fluorescence real-time quantitative PCR is one of the most common

185 methods to detect RIF- and INH-resistant M. tuberculosis (Peng et al. 2016). Other technologies,

186 such as whole-genome sequencing (WGS) (Pankhurst et al. 2016), high-resolution melt (HRM),

187 PCR-single strand conformation polymorphism (PCR-SSCP), and oligonucleotide microarrays

188 (Caoili et al. 2006; Herrmann et al. 2006; Pietzka et al. 2009; Traore et al. 2006), have also been

189 widely used to screen the mutations of candidate genes in DR-TB strains. However, these

190 technologies have their advantages and shortcomings. For example, high quality and various

191 mutation type could be detected by using WGS, but the expensive equipment and reagent limited

192 its usage.

193 Since AS-PCR was first reported in 1989 (Newton et al. 1989), it has been widely used to

194 screen single nucleotide polymorphisms (SNPs) and mutations. Although AS-PCR is considered 
195 as low specificity and sensitivity (Sharma et al. 2016), Onseedaeng et al. identified mutations of

196 the gyrA and parC gene in Escherichia coli (E. coli) with high sensitivity and specificity by

197 using AS-PCR (Onseedaeng \& Ratthawongjirakul 2016). Due to its simple operation, low cost,

198 and relatively high specificity and sensitivity, we successfully used AS-PCR to screen 16

199 mutations in four first-line DR-genes. After optimizing reaction conditions, we successfully

200 amplified the corresponding bands by using AS-PCR primers with high specificity. Most of these

201 primers detected the corresponding mutations when the DNA template reached 500 copy

202 numbers. All these results suggested that optimized AS-qPCR could be used to screen mutations

203 of drug-resistant genes in TB strains with higher specificity and sensitivity. A limitation of

204 current study was the number of drug-resistant mutations in this study was small size. One

205 reason was that no more TB-strains with other drug-resistant mutations were obtained in this

206 experiment; another reason was several drug-resistant mutations could not be well genotyped by

207 using AS-PCR or AS-qPCR method. In further study, we should collect more drug-resistant TB

208 strains from various regions and further optimize AS-PCR condition for rapid screening.

209

210 5. Conclusion

211 In summary, we established an optimized AS-qPCR method to screen mutations in four

212 first-line drug-resistant genes of M. tuberculosis with relatively high specificity and sensitivity.

213 This AS-qPCR could be widely used in the future to rapidly screen mutations in drug-resistant

214 TB strains. 


\section{Supplementary Files}

217 Table S1. Information of AS-PCR primers.

218 Table S2. Information for primers used to construct plasmids.

219 Figure S1. Electrophoresis map of specific tests.

220 Figure S2. Electrophoresis map of sensitivity tests.

221 Figure S3. Melt curves map of real-time quantitative PCR.

\section{Acknowledgments}

224 We thank Mr. Daoqun Li for helping extract DNA from TB strains.

225

226

227

228

\section{References}

Afanas'ev MV, Ikryannikova LN, Il'ina EN, Sidorenko SV, Kuz'min AV, Larionova EE, Smirnova TG, Chernousova LN, Kamaev EY, Skorniakov SN, Kinsht VN, Cherednichenko AG, and Govorun VM. 2007. Molecular characteristics of rifampicinand isoniazid-resistant Mycobacterium tuberculosis isolates from the Russian Federation. J Antimicrob Chemother 59:1057-1064. 10.1093/jac/dkm086

Ahmad S, and Mokaddas E. 2009. Recent advances in the diagnosis and treatment of multidrugresistant tuberculosis. Respir Med 103:1777-1790. 10.1016/j.rmed.2009.07.010

234 Banerjee A, Dubnau E, Quemard A, Balasubramanian V, Um KS, Wilson T, Collins D, de Lisle 
G, and Jacobs WR, Jr. 1994. inhA, a gene encoding a target for isoniazid and ethionamide in Mycobacterium tuberculosis. Science 263:227-230.

Brossier F, Sougakoff W, Bernard C, Petrou M, Adeyema K, Pham A, Amy de la Breteque D,

Comstock GW, Livesay VT, and Woolpert SF. 1974. The prognosis of a positive tuberculin reaction in childhood and adolescence. Am J Epidemiol 99:131-138.

Crofton J, and Mitchison DA. 1948. Streptomycin resistance in pulmonary tuberculosis. $\mathrm{Br}$ Med $J 2: 1009-1015$.

Dalla Costa ER, Ribeiro MO, Silva MS, Arnold LS, Rostirolla DC, Cafrune PI, Espinoza RC, Palaci M, Telles MA, Ritacco V, Suffys PN, Lopes ML, Campelo CL, Miranda SS, Kremer K, da Silva PE, Fonseca Lde S, Ho JL, Kritski AL, and Rossetti ML. 2009. Correlations of mutations in $\mathrm{katG}$, oxyR-ahpC and inhA genes and in vitro susceptibility in Mycobacterium tuberculosis clinical strains segregated by spoligotype families from 
tuberculosis prevalent countries in South America. BMC Microbiol 9:39. 10.1186/1471-

256 2180-9-39

257

258

259

260

261

262

263

264

265

266

267

268

269

270

271

272

273

274

Du J, Pang Y, Ma Y, Mi F, Liu Y, and Li L. 2017. Prevalence of tuberculosis among health care workers in tuberculosis specialized hospitals in China. J Occup Health. 10.1539/joh.160251-BR

Franco-Sotomayor G, Garzon-Chavez D, Leon-Benitez M, de Waard JH, and Garcia-Bereguiain MA. 2018. A First Insight into the katG and rpoB Gene Mutations of Multidrug-Resistant Mycobacterium tuberculosis Strains from Ecuador. Microb Drug Resist. 10.1089/mdr.2018.0203

Guo H, Seet Q, Denkin S, Parsons L, and Zhang Y. 2006. Molecular characterization of isoniazid-resistant clinical isolates of Mycobacterium tuberculosis from the USA. $J$ Med Microbiol 55:1527-1531. 10.1099/jmm.0.46718-0

Herrmann MG, Durtschi JD, Bromley LK, Wittwer CT, and Voelkerding KV. 2006. Amplicon DNA melting analysis for mutation scanning and genotyping: cross-platform comparison of instruments and dyes. Clin Chem 52:494-503. 10.1373/clinchem.2005.063438

Koul A, Arnoult E, Lounis N, Guillemont J, and Andries K. 2011. The challenge of new drug discovery for tuberculosis. Nature 469:483-490. 10.1038/nature09657

Lee JH, Ammerman NC, Nolan S, Geiman DE, Lun S, Guo H, and Bishai WR. 2012. Isoniazid resistance without a loss of fitness in Mycobacterium tuberculosis. Nat Commun 3:753. 
275 Li D, Song Y, Zhang CL, Li X, Xia X, and Zhang AM. 2017. Screening mutations in drugresistant Mycobacterium tuberculosis strains in Yunnan, China. J Infect Public Health 10:630-636. 10.1016/j.jiph.2017.04.008

Newton CR, Graham A, Heptinstall LE, Powell SJ, Summers C, Kalsheker N, Smith JC, and Markham AF. 1989. Analysis of any point mutation in DNA. The amplification refractory mutation system (ARMS). Nucleic Acids Res 17:2503-2516.

Onseedaeng S, and Ratthawongjirakul P. 2016. Rapid Detection of Genomic Mutations in gyrA and parC Genes of Escherichia coli by Multiplex Allele Specific Polymerase Chain Reaction. J Clin Lab Anal 30:947-955. 10.1002/jcla.21961

Pankhurst LJ, Del Ojo Elias C, Votintseva AA, Walker TM, Cole K, Davies J, Fermont JM, 58. 10.1016/S2213-2600(15)00466-X

Peng J, Yu X, Cui Z, Xue W, Luo Z, Wen Z, Liu M, Jiang D, Zheng H, Wu H, Zhang S, and Li Gascoyne-Binzi DM, Kohl TA, Kong C, Lemaitre N, Niemann S, Paul J, Rogers TR, Roycroft E, Smith EG, Supply P, Tang P, Wilcox MH, Wordsworth S, Wyllie D, Xu L, Crook DW, and Group C-TS. 2016. Rapid, comprehensive, and affordable mycobacterial diagnosis with whole-genome sequencing: a prospective study. Lancet Respir Med 4:49Ruppitsch W. 2009. Rapid identification of multidrug-resistant Mycobacterium 
tuberculosis isolates by rpoB gene scanning using high-resolution melting curve PCR analysis. J Antimicrob Chemother 63:1121-1127. 10.1093/jac/dkp124

297

298

299

300

301

Sandy J, Mushtaq A, Kawamura A, Sinclair J, Sim E, and Noble M. 2002. The structure of arylamine $\mathrm{N}$-acetyltransferase from Mycobacterium smegmatis--an enzyme which inactivates the anti-tubercular drug, isoniazid. J Mol Biol 318:1071-1083. $10.1016 / \mathrm{S} 0022-2836(02) 00141-9$

Scorpio A, and Zhang Y. 1996. Mutations in pncA, a gene encoding pyrazinamidase/nicotinamidase, cause resistance to the antituberculous drug pyrazinamide in tubercle bacillus. Nat Med 2:662-667.

Seifert M, Catanzaro D, Catanzaro A, and Rodwell TC. 2015. Genetic mutations associated with isoniazid resistance in Mycobacterium tuberculosis: a systematic review. PLoS One 10:e0119628. 10.1371/journal.pone.0119628

Sharma D, Lather M, Dykes CL, Dang AS, Adak T, and Singh OP. 2016. Disagreement in genotyping results of drug resistance alleles of the Plasmodium falciparum dihydrofolate reductase (Pfdhfr) gene by allele-specific PCR (ASPCR) assays and Sanger sequencing. Parasitol Res 115:323-328. 10.1007/s00436-015-4750-2

Stoffels K, Mathys V, Fauville-Dufaux M, Wintjens R, and Bifani P. 2012. Systematic analysis of pyrazinamide-resistant spontaneous mutants and clinical isolates of Mycobacterium tuberculosis. Antimicrob Agents Chemother 56:5186-5193. 10.1128/AAC.05385-11 
315

316

317

318

319

320

321

322

323

324

325

326

327

328

329

330

331

332

333

334

2015. Molecular analysis of rpoB gene mutations in rifampicin resistant Mycobacterium tuberculosis isolates by multiple allele specific polymerase chain reaction in Puducherry, South India. J Infect Public Health 8:619-625. 10.1016/j.jiph.2015.05.003

Traore H, van Deun A, Shamputa IC, Rigouts L, and Portaels F. 2006. Direct detection of Mycobacterium tuberculosis complex DNA and rifampin resistance in clinical specimens from tuberculosis patients by line probe assay. J Clin Microbiol 44:4384-4388. 10.1128/JCM.01332-06

Tudo G, Rey E, Borrell S, Alcaide F, Codina G, Coll P, Martin-Casabona N, Montemayor M, Moure R, Orcau A, Salvado M, Vicente E, and Gonzalez-Martin J. 2010. Characterization of mutations in streptomycin-resistant Mycobacterium tuberculosis clinical isolates in the area of Barcelona. J Antimicrob Chemother 65:2341-2346. $10.1093 / \mathrm{jac} / \mathrm{dkq} 322$

Villellas C, Aristimuno L, Vitoria MA, Prat C, Blanco S, Garcia de Viedma D, Dominguez J, Samper S, and Ainsa JA. 2013. Analysis of mutations in streptomycin-resistant strains reveals a simple and reliable genetic marker for identification of the Mycobacterium tuberculosis Beijing genotype. J Clin Microbiol 51:2124-2130. 10.1128/JCM.01944-12

Waagmeester A, Thompson J, and Reyrat JM. 2005. Identifying sigma factors in Mycobacterium smegmatis by comparative genomic analysis. Trends Microbiol 13:505-509.

10.1016/j.tim.2005.08.009

WHO. 2018. Global Tuberculosis Report. Available at 
http://www.who.int/tb/publications/factsheet_global.pdf?ua=1.

336 Yuan X, Zhang T, Kawakami K, Zhu J, Li H, Lei J, and Tu S. 2012. Molecular characterization

337 of multidrug- and extensively drug-resistant Mycobacterium tuberculosis strains in

338 Jiangxi, China. J Clin Microbiol 50:2404-2413. 10.1128/JCM.06860-11

339 Zhang Y, and Yew WW. 2009. Mechanisms of drug resistance in Mycobacterium tuberculosis.

$340 \quad$ Int J Tuberc Lung Dis 13:1320-1330.

341 Zhao LL, Liu HC, Sun Q, Xiao TY, Zhao XQ, Li GL, Zeng CY, and Wan KL. 2015.

342 Identification of mutations conferring streptomycin resistance in multidrug-resistant

343 tuberculosis of China. Diagn Microbiol Infect Dis 83:150-153.

$344 \quad$ 10.1016/j.diagmicrobio.2015.06.020

345 Zhao Y, Xu S, Wang L, Chin DP, Wang S, Jiang G, Xia H, Zhou Y, Li Q, Ou X, Pang Y, Song

Zignol M, Dean AS, Falzon D, van Gemert W, Wright A, van Deun A, Portaels F, Laszlo A, Espinal MA, Pablos-Mendez A, Bloom A, Aziz MA, Weyer K, Jaramillo E, Nunn P, Floyd K, and Raviglione MC. 2016. Twenty Years of Global Surveillance of Y, Zhao B, Zhang H, He G, Guo J, and Wang Y. 2012. National survey of drug-resistant tuberculosis in China. N Engl J Med 366:2161-2170. 10.1056/NEJMoa1108789

353 


\section{Figure 1}

Figure 1. Detection of 16 mutations in four first-line drug-resistance genes by using ASPCR.

M means DNA marker DL2000; $m$ and w mean the AS-PCR primers were used to screen mutation and wildtype alleles, respectively. NC means negative control.
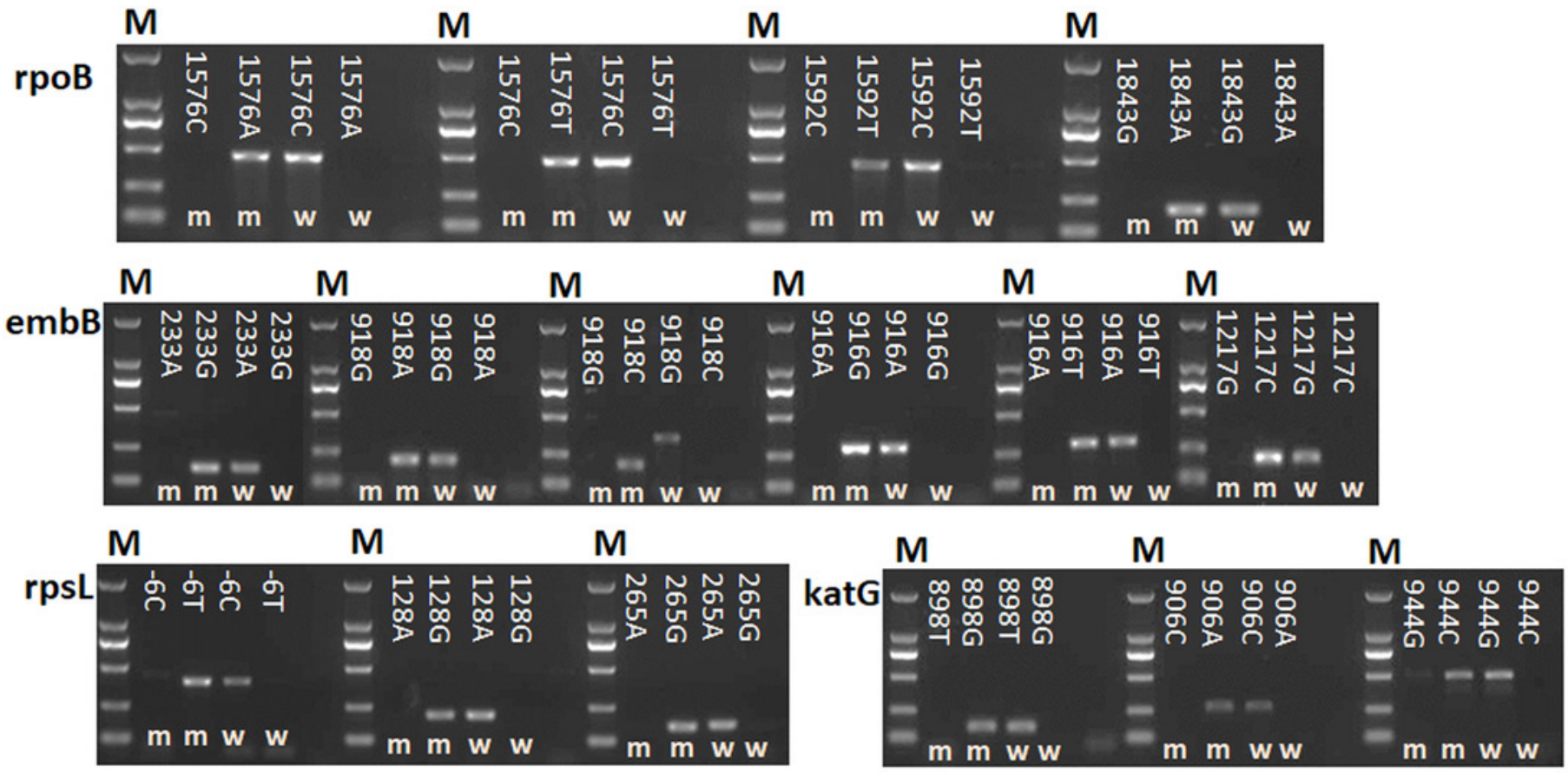


\section{Figure 2}

Figure 2. Specificity of AS-PCR primers for A128G in the rpsL gene.

(A) PCR were performed by using fourteen DNA templates with allele A and wildtype AS-PCR primers. (B) PCR were performed by using fourteen DNA templates with allele A and mutation AS-PCR primers. (C) PCR were performed by using eight DNA templates with allele $G$ and mutation AS-PCR primers. (D) PCR were performed by using eight DNA templates with allele $\mathrm{G}$ and wildtype AS-PCR primers. Fragments at 206 bp mean the specific product by ASPCR primers; fragments at $104 \mathrm{bp}$ mean the inner control product by inner primers; NC means negative control. 

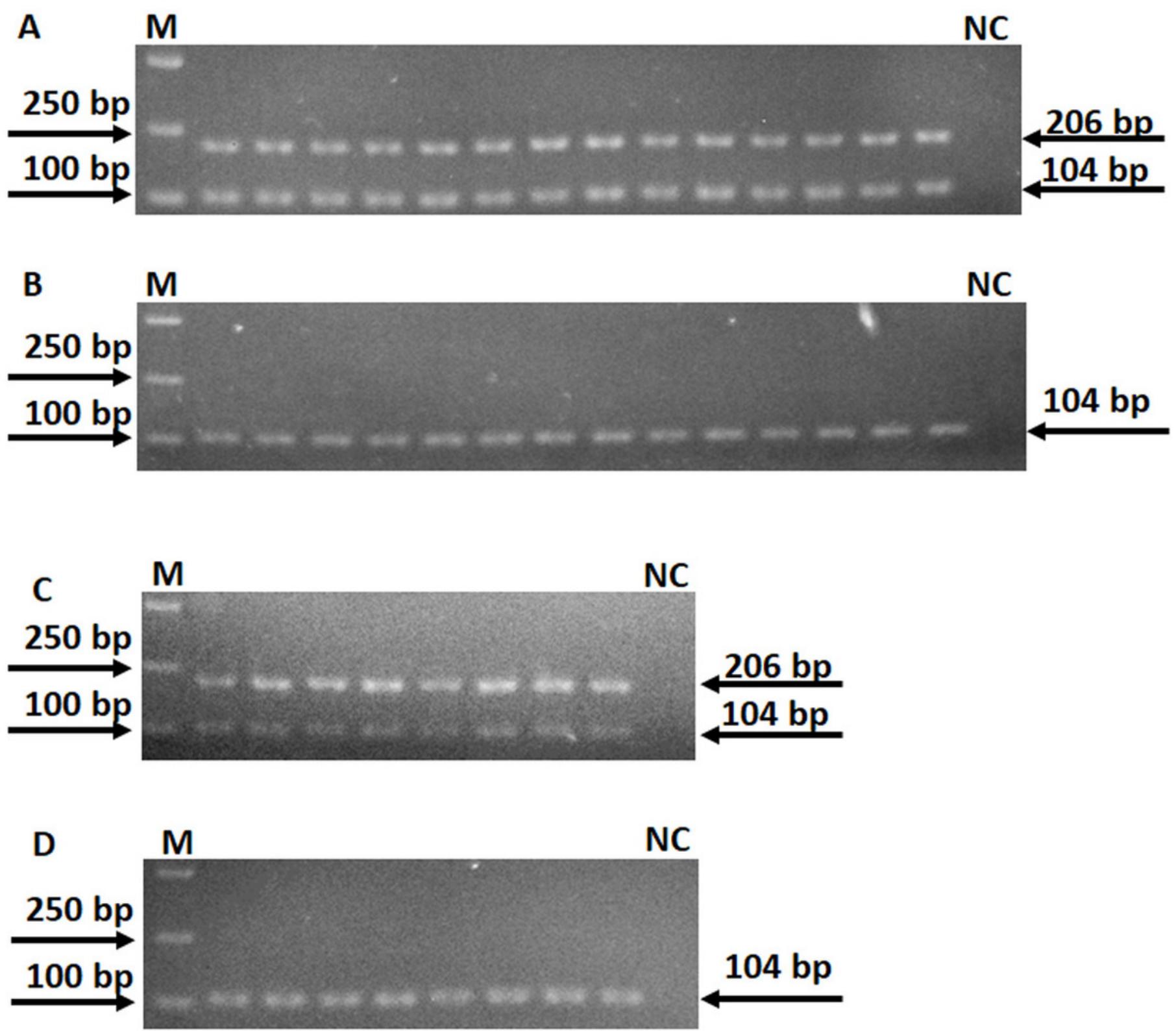


\section{Figure 3}

Figure 3. Sensitivity of AS-PCR primers for A128G in the rpsL gene.

M means DNA marker DL2000; $\mathrm{m}$ and w mean the AS-PCR primers were used to screen mutation and wildtype alleles, respectively.

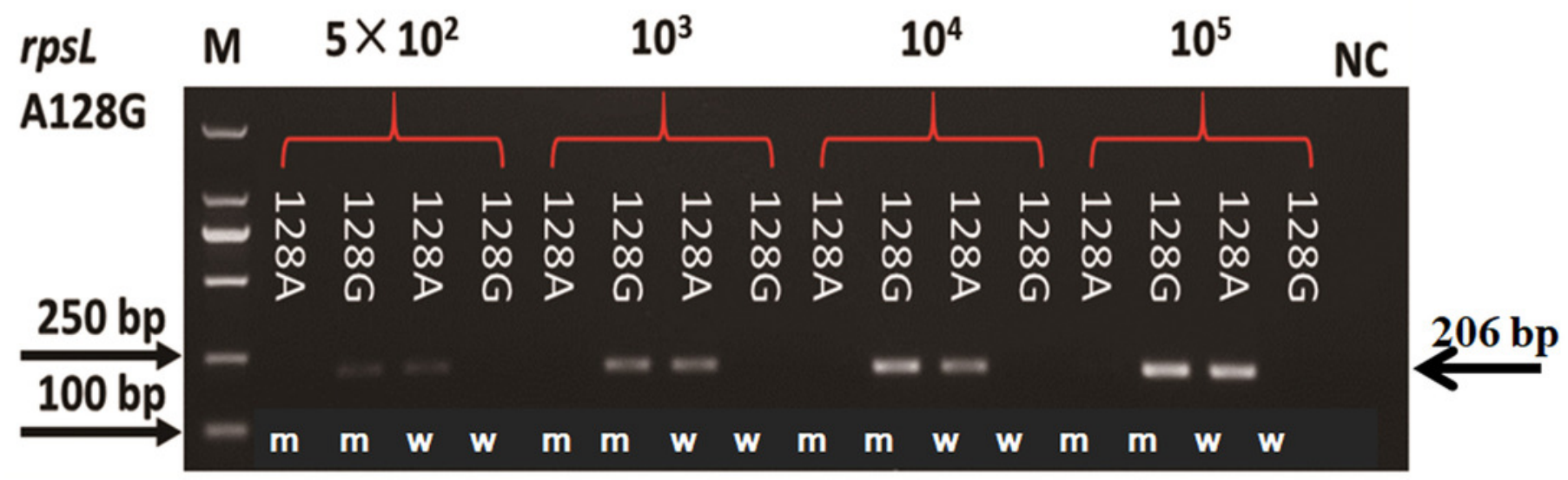




\section{Figure 4}

Figure 4. Detecting allele type of A128G in the rpsL genes by using AS-PCR primers and real-time quantitative PCR.

(A) Melt curves of product by using DNA template with allele A. (B) Melt curves of product by using DNA template with allele G.

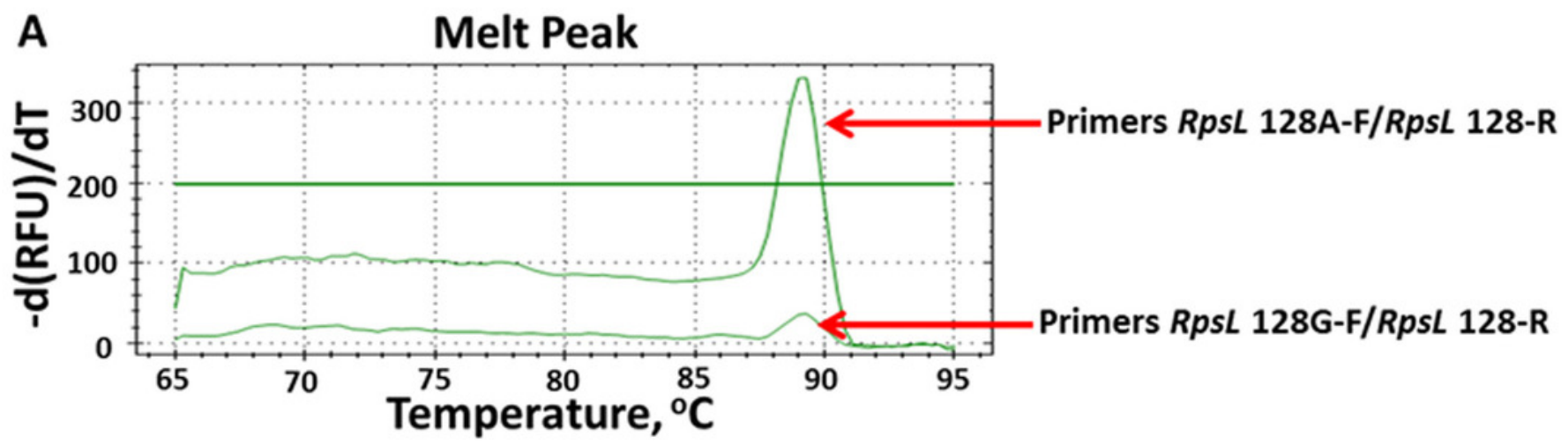

B

Melt Peak

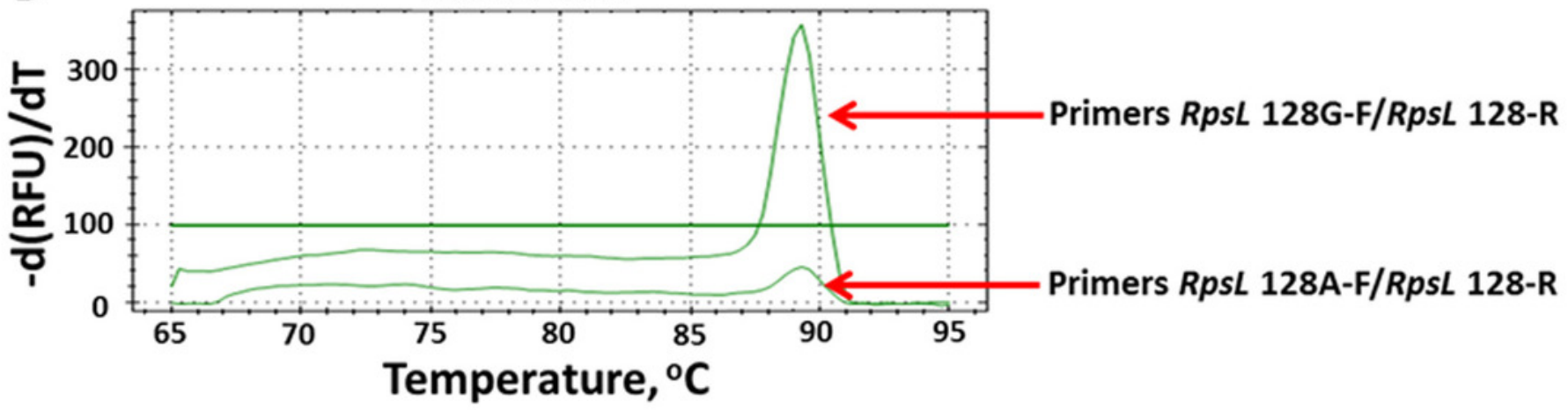

